\title{
MRI Evaluation of Hepatic Iron Overload in Chronically Transfused P-Thalassemic Children
}

\author{
SAMAR Sh. ALI EMAM, M.Sc.; ABEER MAGHAWRY A. MOHAMED, M.D. and \\ SUSAN A.A. ABDUL RAHIM, M.D.
}

The Department of Radiology, Faculty of Medicine, Ain Shams University

\begin{abstract}
Background: Patients with chronic hemolytic anemia like thalassemia need repeated blood transfusions which lead to iron overload. MRI has emerged for the noninvasive assessment of iron overload in various tissues.

Aim of Study: The aim of this study is to assess the role of MRI in the evaluation of hepatic iron overload in multi transfused P-Thalassemic children and to correlate the results with serum ferritin levels.

Patients and Methods: In 45 cases of multi-transfused child with thalassemia, Liver Iron Concentration (LIC) was measured by MRI T2* and compared to serum ferritin (traditional marker of iron overload).

Results: There were a significant positive correlation between serum ferritin and LIC $(r=0.557$ and $p<0.01)$ when SF level below $4000 \mathrm{ng} / \mathrm{ml}$, and the correlation became very weak when serum ferritin above $4000 \mathrm{ng} / \mathrm{ml}$. Also, there were a significant negative correlation of LIC with T2* ( $r=-0.999$ and $p<0.01)$ and a significant positive correlation with $\mathrm{R} 2 *$ $(r=1.000$ and $p<0.01)$ and no significant correlation with age, sex, splenectomy and frequency of blood transfusion.

Conclusion: MRI T2* provides accurate reproducible and non-invasive technique for assessing tissue iron concentration. Through the widespread application of this technique it should be possible to improve management of tissue iron overload allowing earlier chelation intensification.
\end{abstract}

Key Words: Thalassemia -MRI T2* - Liver iron concentration.

\section{Introduction}

0 -THALASSEMIA major is a hereditary hemolytic anemia characterized by ineffective erythropoiesis and hemolysis. Thalassemia is a major health problem in Egypt since it is estimated that out of 1.5 million live births, 1000 children with thalassemia are born annually [1] .

The treatment of choice for thalassemia patients is blood transfusions. Although it is a life-saving

Correspondence to: Dr. Samar Sh. Ali Emam, E-Mail: samarsherif91@gmail.com measure, repeated transfusions result in iron deposition within the tissues. This iron overload is exaggerated by intestinal iron absorption stimulated by tissue hypoxia, apoptosis of defective erythroid precursors generated by ineffective erythropoiesis, and hemolysis of native and transfused red blood cells. After repeated transfusions without the use of appropriate chelation therapies, the resulting accumulation of iron may cause endocrine and cardiac dysfunction, hepatic effects, and finally, patient death, which commonly occurs in the second decade of life [2]

Liver is the primary site for iron storage in patients with hemochromatosis or transfusiondependent anemia; therefore, Liver Iron Concentration (LIC) accurately reflects total body iron stores [3].

Ferritin is a metalloprotein that is found in cells. It stores and releases iron in a controlled manner. In normal individuals, a small amount appears in the circulation and in general reflects the total body iron. It is an acute phase reactant, and the serum levels may be disproportionately greater than the degree of iron loading in infections, inflammatory states, liver dysfunction and malignancies [4].

Liver core biopsy has a high sampling variability, which limits its utility for quantitative assessment of diffuse liver disease because regional heterogeneity may occur [5] . Furthermore, liver iron overload cannot be quantified reliably by using US or CT, although severe iron overload can be detected by using CT. For these reasons, noninvasive imaging techniques that allow visualization of the entire liver are desirable for measurement of liver iron [6]. 
MRI is a key tool in the current management of patients with thalassemia. Given its capability of assessing iron overload in different organs noninvasively and without contrast, it has significant advantages over other metrics, including serum ferritin and liver biopsy. LIC can be measured either with relaxometry methods $\mathrm{T} 2 * / \mathrm{T} 2$ or signal intensity ratio techniques [7].

MRI machines can generate images at various observation or "echo" times to vary the contrast among different organs. All organs darken with increasing echo time, but those containing iron darken more rapidly Fig. (1). This is due to the fact that, the magnetic field in a clinical scanner is extremely homogenous, but iron within the tissues creates local magnetic field disturbances that cause the images to darken faster. T2* represents the echo time necessary for a tissue to become twice as dark. Alternatively, image darkening can be expressed by $\mathrm{R} 2 *$, its rate of darkening. Some investigators prefer to report $\mathrm{R} 2 *$ values rather than $\mathrm{T} 2 *$ values, because $\mathrm{R} 2 *$ is directly proportional to iron concentration. $\mathrm{R} 2 *$ values are simply $1000 / \mathrm{T} 2 *$ and vice versa, making it easily to convert one representation to another $[8]$.

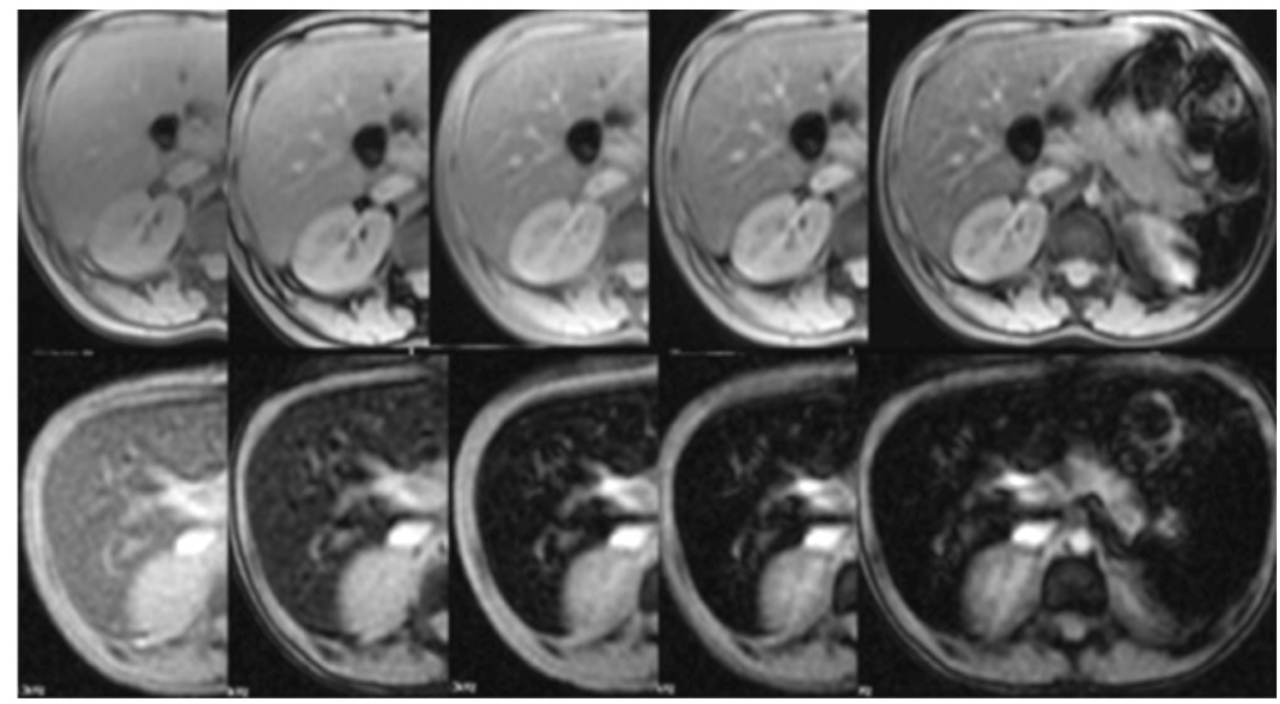

Fig. (1): Hepatic MRI GRE sequence; Up: In images of the 5 initial echos, slow signal decay can be noted in the liver. The R2* is $47 \mathrm{~Hz}$, which corresponds to an LIC of $1.39 \mathrm{mg}$ Fe/g dry liver, indicating an absence of iron overload. Down: There is rapid decay in the signal of the liver. The R2* is $700 \mathrm{~Hz}$, which corresponds to $18 \mathrm{mg} \mathrm{Fe} / \mathrm{g}$ dry liver, indicating severe iron overload.

\section{Patients and Methods}

This study was carried out upon 45 multi transfused $\beta$-thalassaemic children from January 2019 to June 2019. The patients were referred for MRI assessment of liver siderosis at our institute and undergo MRI which includes measurement of liver T2*.

We studied 45 patients with B-thalassemia (23 females and 22 males), with a mean age of $12.4 \pm$ 2.74 (ranged between 6-15 years). The exclusion criteria were as follows: Patients younger than 5 years, patients with liver decompansatoin, patients who are contraindicated to perform MRI and patients who refused the examination. All patients were on regular transfusion programme and on iron chelation therapy since early childhood years.

The present study considers the following parameters: (A) Serum ferritin, (B) Liver iron concentration, (C) Liver $\mathrm{T} 2$ relaxation time.
Ethical committee approval to perform MRI $\mathrm{T} 2 *$ technique and patients or guardians consents were obtained.

\section{MRI technique:}

The MRI study was performed in MRI Unit of Radiology Department, Ain Shams University Hospitals using super conductive MR scanner (Philips Achieva-XR 1.5 Tesla).

\section{Using a standard scanning protocol:}

- All metallic objects were removed from the patient's body.

- The patient was supine, head first into MRI machine and we used a body coil.

- Patients were instructed about the importance of being calm with no motion throughout the time of examination.

- MRI protocol of the hepatic iron overload including: 
1- Multiple axial gradient echo (GRE) images with different TE, TR was $100 \mathrm{~ms}$, Flip angle $=20$ and slice thickness was $10 \mathrm{~mm}$ with no gap interval.

2- By the use of post image processing specific software system, Region of Interest (ROI) will be drawn. Signal intensity analysis was performed in the periphery of the liver away from the large central vessels.

3- The TEs and ROI values will be inserted in the columns of the spread sheet program that supports an MS-Excel file.
4- Automatically a curve will be generated and T2*, R2*, LIC will be calculated Fig. (2).

5- The software also provides a reference table for the results Fig. (3).

In heavily-iron loaded tissues, signal decay occurs rapidly with noise dominating the signal at later echo times. To minimize the potential for noise to cause over-estimation of $\mathrm{T} 2 *$ in heavily iron-loaded tissues, these later points are not used for curve fitting for very low values of $\mathrm{T} 2 *$ and we did truncation.

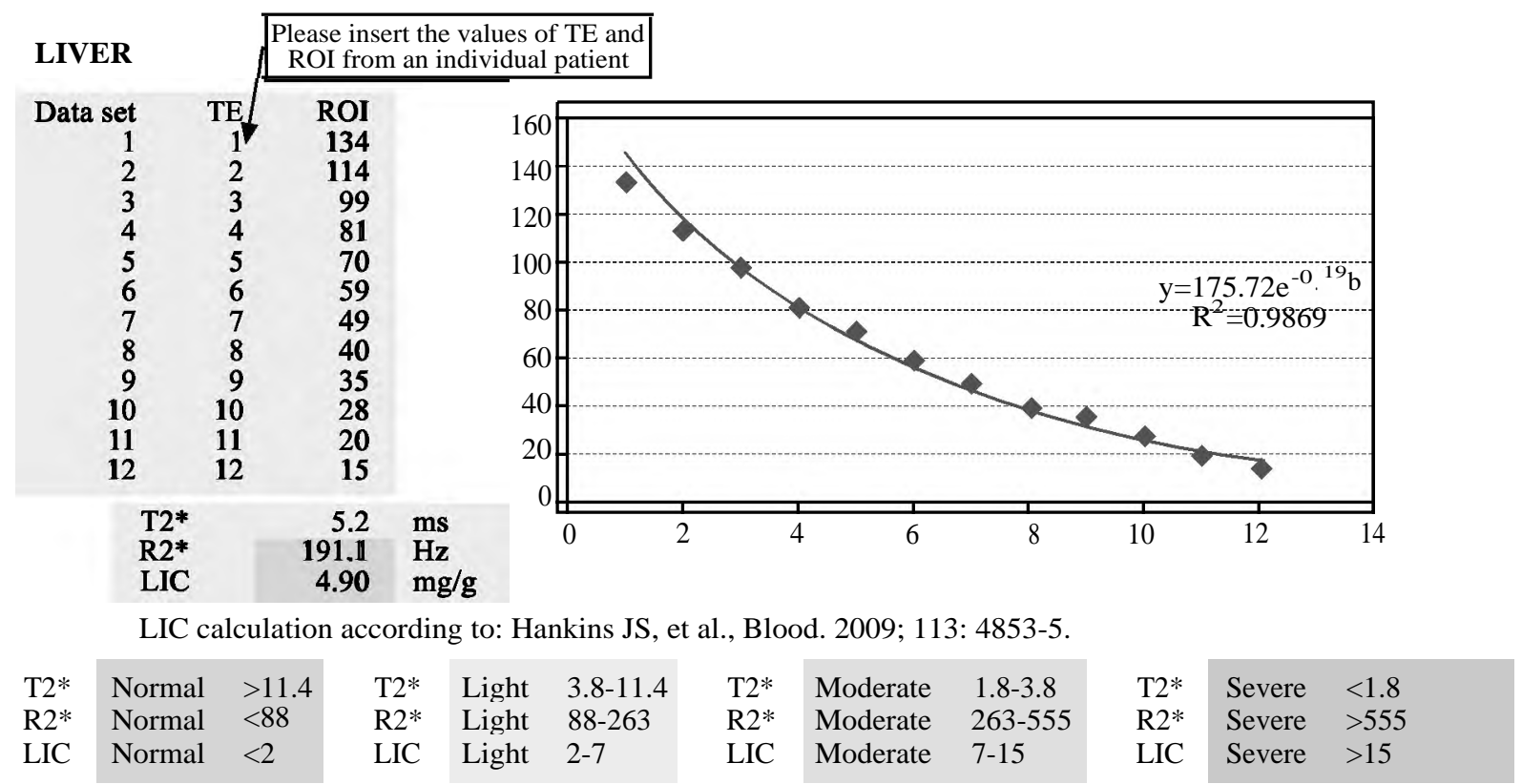

Fig. (2): Sample screenshot of the results section of the software with the automatic curve generation, T2*, R2*, and LIC displayed. Along with the results, the software also provides a reference table.

\begin{tabular}{llllllllllll}
\hline \hline T2* & Normal & $>11.4$ & T2* & Light & $3.8-11.4$ & T2* & Moderate & $1.8-3.8$ & T2* & Severe & $<1.8$ \\
R2* & Normal & $<88$ & R2* & Light & $88-263$ & R2* & Moderate & $263-555$ & R2* & Severe & $>555$ \\
LIC & Normal & $<2$ & LIC & Light & $2-7$ & LIC & Moderate & $7-15$ & LIC & Severe & $>15$ \\
\hline
\end{tabular}

Fig. (3): Sample screenshot of the reference table provided by the software.

\section{Results}

The study included 45 patients: 22 males $(48.9 \%)$ and 23 females (51.1\%). The ages of the patients ranged from 6 to 15 years, with a mean of $12.4 \pm 2.74$ years. In our study 20 patients underwent splenectomy representing $44.4 \%$ of cases. All the patients received iron chelation therapy since early childhood years (Table 1).

The frequency of blood transfusion ranged from 10 to 40 days and the patients received regular blood transfusion as follows: $1(2.2 \%)$ received blood transfusion every 10 days, $14(31.1 \%)$ every 15 days, $14(31.1 \%)$ every 21 days, $14(31.1 \%)$ every 30 days and 2 (4.4\%) every 40 days Fig. (4).
Table (1): Distribution of the studied cases according to different parameters $(n=45)$.

\begin{tabular}{ll}
\hline Age: & \\
Range & $6-15$ \\
Mean \pm SD & $12.40 \pm 2.74$ \\
Sex: & \\
$\quad$ Female & $23(51.1 \%)$ \\
$\quad$ Male & $22(48.9 \%)$ \\
Splenectomy: & \\
$\quad$ No & $25(55.6 \%)$ \\
$\quad$ Yes & $20(44.4 \%)$ \\
Chelation therapy & $45(100.0 \%)$ \\
Frequency of blood transfusion (in days): & \\
$\quad$ Mean \pm SD & $22.53 \pm 7.35$ \\
$\quad$ Range & $10-40$ \\
\hline
\end{tabular}




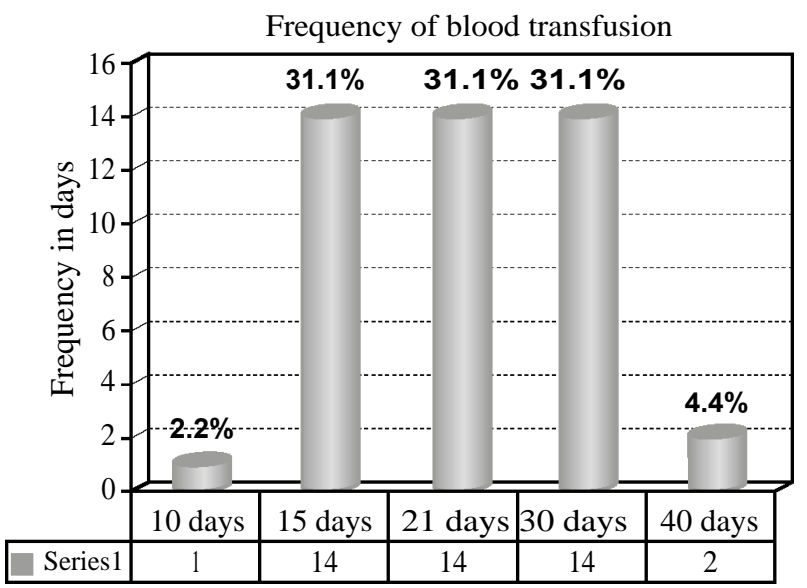

Fig. (4): Frequency of blood transfusion among study cases.

The serum ferritin levels in the studied patients ranged from $360-10000 \mathrm{ng} / \mathrm{ml}$, with a median value of 2707.7. There were 35 cases with serum ferritin $<4000 \mathrm{ng} / \mathrm{ml}$ representing $77.8 \%$ and 10 cases $>4000 \mathrm{ng} / \mathrm{l}$ representing $22.2 \%$ (Table 2 ).

$\mathrm{T} 2 *$ value ranged from 0.8 to 15.7 with a median value of $2 \mathrm{~ms}$ while $\mathrm{R} 2 *$ value ranged from 63.6 to 1181.9 with a median value of $512.4 \mathrm{~Hz}$ (Table 2).

Table (2): Distribution of the studied cases according to serum ferritin and MRI parameters $(n=45)$.

\begin{tabular}{ll}
\hline Serum ferritin: & \\
Median (IQR) & $2707.7(1572-3496.4)$ \\
Range & $360-10000$ \\
Cases $<4000$ & $35(77.8 \%)$ \\
Cases $>4000$ & $10(22.2 \%)$ \\
$T 2^{*}:$ & \\
Median (IQR) & $2(1.3-5)$ \\
Range & $0.8-15.7$ \\
$R 2^{*}:$ & \\
Median (IQR) & $512.4(200.6-776)$ \\
Range & $63.6-1181.9$ \\
LIC: & \\
Median (IQR) & $13.9(5.1-21.3)$ \\
Range & $1.33-32.6$ \\
\hline
\end{tabular}

The LIC ranged from 1.33 to $32.6 \mathrm{mg} / \mathrm{g}$ with a median value of 13.9 (Table 2) and its characteristics among the studied cases were as follows: 1 (2.2\%) had no overload, $12(26.7 \%)$ had mild overload, $14(31.1 \%)$ had moderate overload, and $18(40 \%)$ had severe overload.

There were a strong negative correlation of LIC with T2* $(r=-0.999$ and $p<0.01)$ and strong positive correlation with $\mathrm{R} 2 *$ ( $r=1.000$ and $p<0.01$ ) and with serum ferritin $(r=0.596$ and $p<0.01)$ Fig. (5) and no significant correlation with age, sex, splenectomy and frequency of blood transfusion (Tables 3,4).

Table (3): Correlation of LIC with different parameters.

\begin{tabular}{lcr}
\hline & \multicolumn{2}{c}{ LIC } \\
\cline { 2 - 3 } & $r$ & $p$-value \\
\hline $\mathrm{T} 2^{*}$ & -0.999 & 0.000 \\
$\mathrm{R} 2 *$ & 1.000 & 0.000 \\
Serum ferritin & 0.596 & 0.000 \\
Age & -0.073 & 0.632 \\
Frequency of blood transfusion & 0.032 & 0.837 \\
\hline
\end{tabular}

$p$-value $>0.05$ : Non Significant (NS).

$p$-value $<0.05$ : Significant $(\mathrm{S})$

$p$-value <0.01: Highly Significant (HS).

Table (4): Correlation of LIC with other different parameters.

\begin{tabular}{|c|c|c|c|c|c|}
\hline & \multicolumn{2}{|l|}{ LIC } & \multirow{2}{*}{$\begin{array}{c}\text { Test } \\
\text { value } \\
\quad \neq\end{array}$} & \multirow{2}{*}{$\begin{array}{c}p- \\
\text { value }\end{array}$} & \multirow{2}{*}{ Sig } \\
\hline & Median (IQR) & Range & & & \\
\hline \multicolumn{6}{|l|}{ Sex: } \\
\hline Female & $14.2(5.25-23)$ & $3-32.6$ & -0.965 & 0.335 & NS \\
\hline Male & $13.55(3.96-17.74)$ & $1.33-30.7$ & & & \\
\hline \multicolumn{6}{|c|}{ Splenectomy: } \\
\hline No & $14.1(7-19.8)$ & $2.36-30.7$ & -0.148 & 0.882 & NS \\
\hline Yes & $12.85(4.25-22.67)$ & $1.33-32.6$ & & & \\
\hline
\end{tabular}

$p$-value $>0.05$ : Non Significant (NS).

$p$-value $<0.05$ : Significant (S).

$p$-value $<0.01$ : Highly Significant (HS).

Serum ferritin $<4000 \mathrm{ng} / \mathrm{ml}$ showed strong negative correlation with $\mathrm{T} 2 *$ Fig. (6) ( $r=-0.560$ and $p<0.01)$ and strong positive correlation with $\mathrm{R} 2 *$ $(r=0.562$ and $p<0.01)$ and with LIC $(r=0.557$ and $p<0.01)$. However, there was no correlation between serum ferritin and different MRI parameters when serum ferritin $>4000 \mathrm{ng} / \mathrm{ml}$ (Table 5).

Table (5): Correlation between MRI finding and serum ferritin.

\begin{tabular}{|c|c|c|c|c|c|c|}
\hline & \multicolumn{2}{|c|}{$\mathrm{T} 2 *$} & \multicolumn{2}{|c|}{$\mathrm{R} 2 *$} & \multicolumn{2}{|c|}{ LIC } \\
\hline & $r$ & $\begin{array}{c}p- \\
\text { value }\end{array}$ & $r$ & $\begin{array}{c}p- \\
\text { value }\end{array}$ & $r$ & $\begin{array}{c}p- \\
\text { value }\end{array}$ \\
\hline Serum ferritin (all cases) & -0.598 & 0.000 & 0.598 & 0.000 & 0.596 & 0.000 \\
\hline Serum ferritin $<4000$ & -0.560 & 0.000 & 0.562 & 0.000 & 0.557 & 0.001 \\
\hline Serum ferritin $>4000$ & 0.056 & 0.877 & -0.079 & 0.829 & -0.079 & 0.829 \\
\hline
\end{tabular}

$p$-value $>0.05$ : Non Significant (NS).

$p$-value $<0.05$ : Significant (S).

$p$-value <0.01: Highly Significant (HS). 


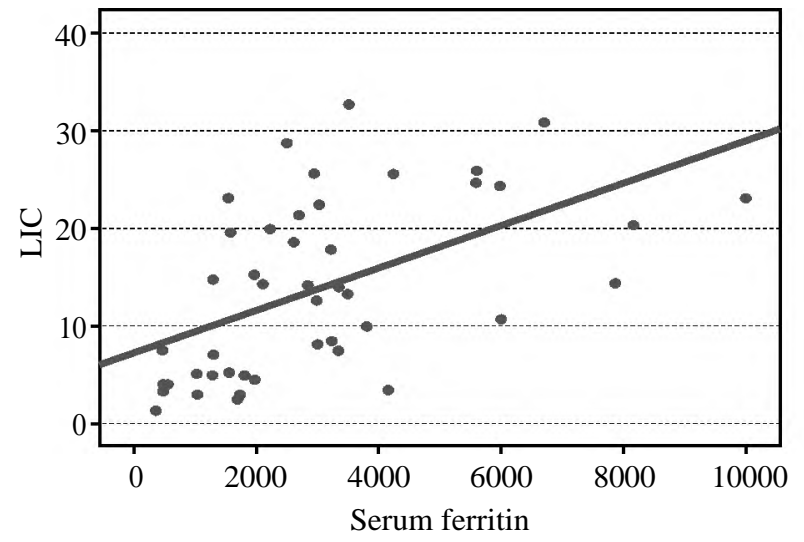

Fig. (5): Correlation of LIC with serum ferritin showing a highly significant positive correlation.

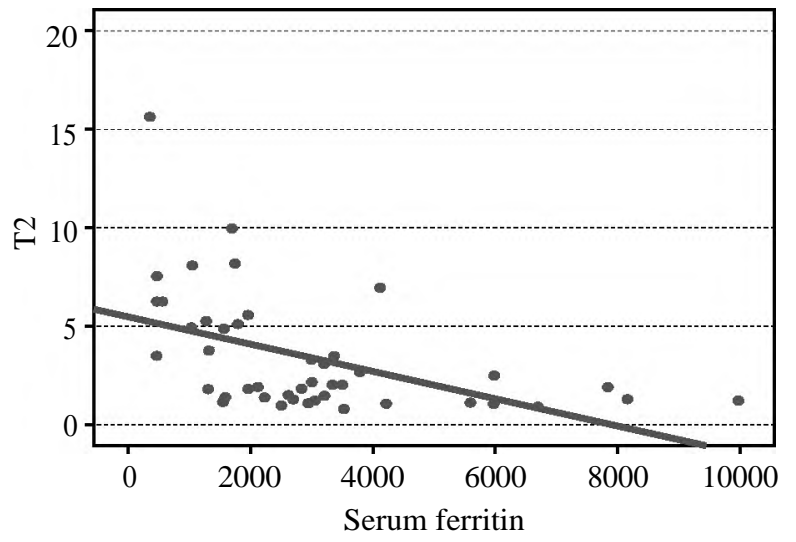

Fig. (6): Correlation of T2* with serum ferritin showing a highly significant negative correlation.
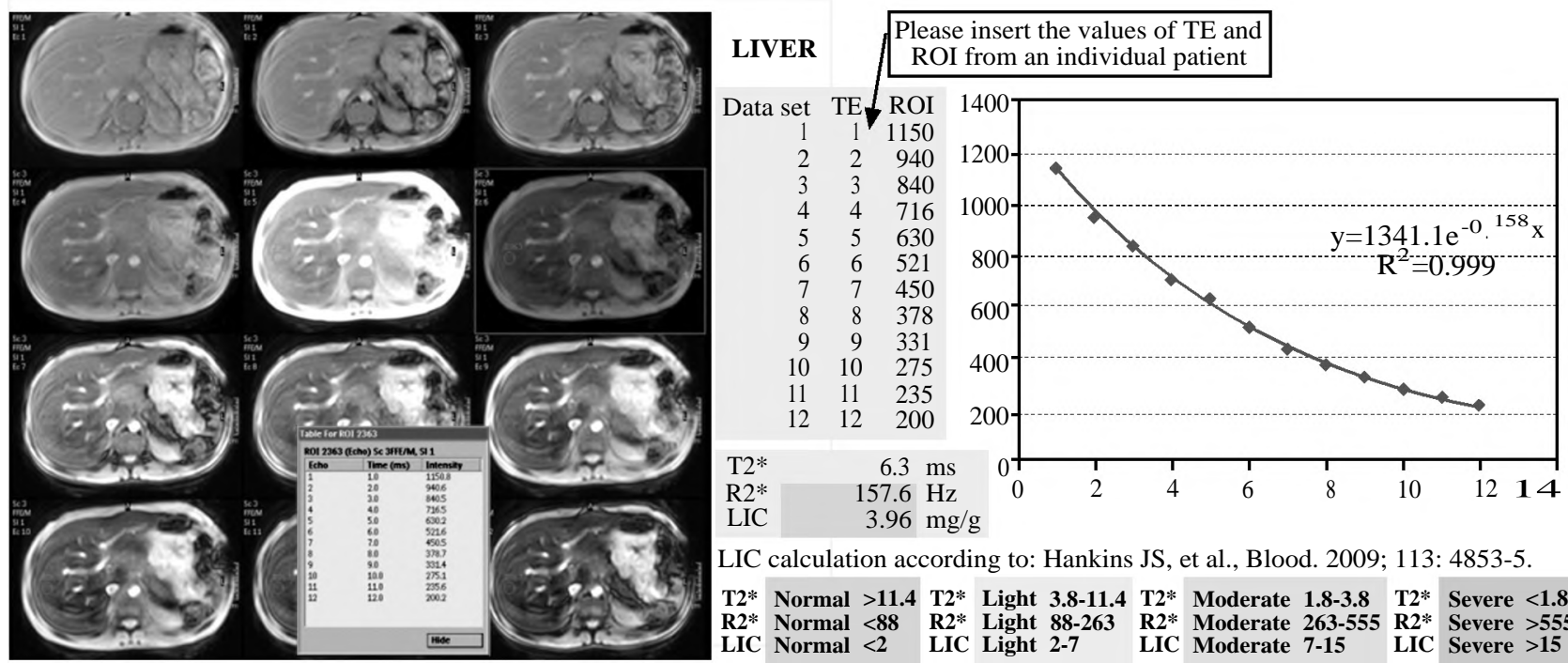

LIC calculation according to: Hankins JS, et al., Blood. 2009; 113: 4853-5.

T2* Normal >11.4 T2* Light 3.8-11.4 T2* Moderate 1.8-3.8 T2* Severe $<1.8$ R2* Normal $<88 \quad$ R2$^{*}$ Light 88-263 R2* Moderate 263-555 R2* Severe $>555$ LIC Normal $<2$ LIC Light 2-7 2 LIC Moderate 7-15 LIC Severe $>15$

Figs. $(7,8): 15$ years old male on regular blood transfusion every 21 days with history of splenectomy. Serum ferritin=472.6ng/ml. The result was mild hepatic iron overload with an LIC of $3.96 \mathrm{mg} / \mathrm{g}$.
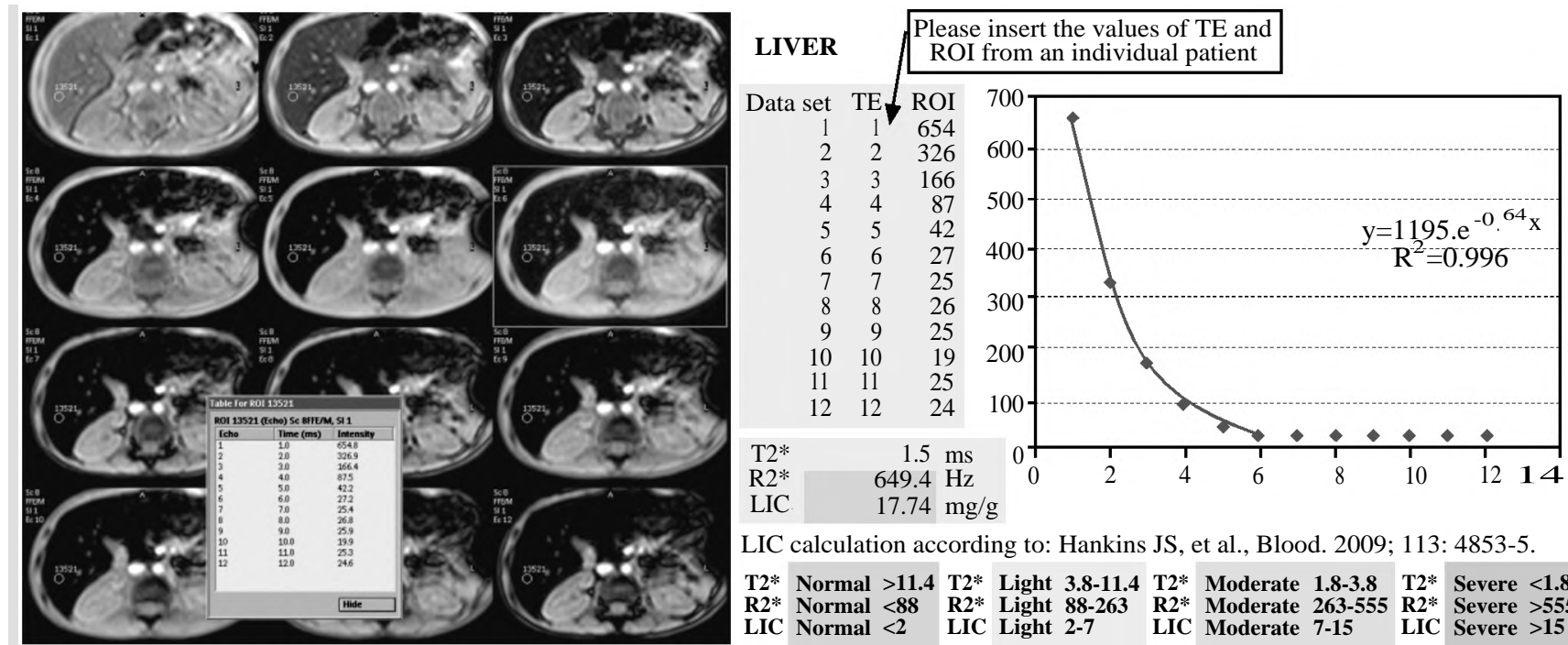

LIC calculation according to: Hankins JS, et al., Blood. 2009; 113: 4853-5.

T2* Normal >11.4 T2* Light 3.8-11.4 T2* Moderate 1.8-3.8 $\mathrm{T}^{*}$ * Severe $<1.8$ R2* Normal $<88$ R2* Light 88-263 R2* Moderate 263-555 R2* Severe $>555$ LIC Normal $<2$ LIC Light $2-7$ LIC Moderate 7-15 LIC Severe $>15$

Figs. (9,10): 6 years old male on regular blood transfusion every 15 days and no history of splenectomy. Serum ferritin=3220ng/ml. The result was severe hepatic iron overload with hepatic LIC of $17.74 \mathrm{mg} / \mathrm{g}$. 


\section{Discussion}

Thalassemia is a serious disease and one of its major complication is iron overload because of repeated blood transfusion as a long term treatment; therefore the quantitative determination of the deposition of iron in various organs in multitransfused patients with thalassemia is of outmost importance for the effective monitoring of iron chelation therapy. In the past, the liver iron concentration was quantitated only by biopsy and ferritin levels [9]

However, Serum Ferritin (SF) level alone is not fully acceptable. It is widely recognized as an acute phase reactant and marker of acute and chronic inflammation, and is nonspecifically elevated in a wide range of inflammatory conditions, including chronic liver and kidney diseases, rheumatoid arthritis and other autoimmune disorders, acute infection, and malignancy [10]

Tissue biopsy is the traditional gold standard for diagnosis of iron overload, but iron deposition tends to be patchy. So, biopsies may miss the areas of deposition and provide a false negative result plus it is an invasive risky procedure. Also the discomfort and risk that a liver biopsy causes to the patients along with the weak correlation between liver fibrosis and iron concentration diminishes the value of this examination, especially when this has to be repeated serially [9]

Therefore, the use of accurate, non-invasive, rapid and single MRI sequences such as T2* for the detection and quantification of hepatic iron overload is a major step for the monitoring of chelation therapy and the diagnosis of organ siderosis among thalassemia patients [11].

The objective of our study was to highlight the effectiveness of MRI in measuring the amount of iron deposited in the liver of regularly transfused patients with thalassemia.

We included 45 patients with B-thalassemia Major (23 females and 22 males), with a mean age of 12.40 \pm 2.74 years (ranged between: 6-15 years). All patients were on regular transfusion and on iron chelation therapy.

In our study, there were no significant correlations between LIC and age, sex or the rate of blood transfusion. This result is in agreement with many previous studies conducted by Pakbaz et al. [12], Musallam et al. [13] and Cappellini et al. [14], who reported that there was no clear correlation between any $\beta$-thalassemic patients' characteristics and LIC.
Also, in our study there was no significant correlation between LIC and splenectomy in keeping with other studies done by Papakonstantinou et al. [15], Angelucci et al. [16] and El Shanshory et al. [17], who reported that splenectomy and its timing had little insignificant effect on LIC and total body iron.

Our study showed a negative correlation between LIC and T2* and positive correlation between LIC and R2*. These findings agreed with other studies conducted by Fahmy et al. [9], Anderson [11] and El Shanshory et al. [17] who reported that LIC is greatly associated with $\mathrm{T} 2 *$ and $\mathrm{R} 2 *$ and the larger the liver iron overload, the greater the decrease of Signal Intensity (SI) on MR images which is represented with $\mathrm{T} 2 *$ as liver parenchyma darkens progressively with increased TE.

These results can be explained by the paramagnetic properties of iron that can affect susceptibility of tissue and produce changes in the magnetic field so that high iron overload leads to decrease in $(\mathrm{T} 2 *, \mathrm{~T} 2)$ and increase in (R2, R2*). Another explanation of this finding could be attributed to the mechanism of MRI, which does not image the iron directly, but instead images water protons as they diffuse near iron deposits in the tissue of interest such as heart and liver. The iron acts as little magnets, destroying the homogeneity of the magnetic field in iron laden tissues. The moving water protons each experience significantly different magnetic profile and become desynchronized from one another. This causes the image to darken at a rate proportional to the iron concentration [17]

Majd et al., [18] showed that serum ferritin has statistically significant positive correlation with LIC and significant negative correlation with $\mathrm{T} 2 *$ of Liver which agreed with our results. However, these correlations became non significant when the SF was above $4000 \mathrm{ng} / \mathrm{ml}$; among our patients there were ten patients with very high SF level above $4000 \mathrm{ng} / \mathrm{ml}$ including one case with mild LIC and two cases with moderate LIC. This is in agreement with other studies conducted by Azarkeivan et al. [4] and Neufeld [19] who reported that the correlation between serum ferritin and liver T2* and LIC is greatly weakened in patients with serum ferritin level $>4000 \mathrm{ng} / \mathrm{ml}$ and serum ferritin as a surrogate measure of LIC is highly varied.

These results could be explained by many factors. Serum ferritin can be affected by the presence of hepatitis $\mathrm{C}$ which increases SF. Another explanation of this finding is that SF which is an acute 
phase reactant generated in response to inflammation, contains much less iron than normal ferritin and this is very apparent in patients with $\beta$ thalassemia and hepatitis $C$ virus 20 and interpretation of serum ferritin values may be complicated by a variety of conditions that alter concentrations independently of changes in the body iron burden including fever, acute and chronic hepatic damage, hemolysis and ineffective erythropoiesis; all of which are common in patients with $\beta$-thalassemia major [21]

In conclusion MRI T2* provides accurate reproducible and non-invasive technique for assessing tissue iron concentration. Through the widespread application of this technique it should be possible to improve management of tissue iron overload allowing earlier chelation intensification.

\section{References}

1- YOUSSEF S.M., EL ALFY M.S., OSMAN A.L., KHATTAB D.A., et al.: Rapid detection of multiple $\beta$-globin gene mutations by a real-time polymerase chain reaction in $\beta$-thalassemia carriers. Egypt J. Haematol., 37 (3): 147$55,2012$.

2- CLAUDE B. and SCOTT B.: Magnetic resonance imaging quantification of liver iron. Magn. Reson. Imaging Clin. N. Am., 18 (3): 359, 2010.

3- TZIOMALOS K. and PERIFANIS V.: Liver iron content determination by magnetic resonance imaging. World Journal of Gastroenterology, 16 (13): 1587-97, 2010.

4- AZARKEIVAN A., HASHMIEH M., AKHLAGHPOOR S., SHIRKAVAND A., et al.: Relation between serum ferritin and liver and heart MRI T2* in beta thalassemia major patients. Eastern Mediterranean Health J., 19 (8): 727-32, 2013.

5- RATZIU V., CHARLOTTE F., HEURTIER A., GOMBERT S., GIRAL P., et al.: Sampling variability of liver biopsy in nonalcoholic fatty liver disease. Gastroenterology, 128 (7): 1898-906, 2005.

6- SIRLIN C.B. and REEDER S.B.: Magnetic resonance imaging quantification of liver iron. Magn. Reson. Imaging Clin. N. Am., 18 (3): 359-81, 2010.

7- FERNANDES J.L.: MRI for Iron Overload in Thalassemia Hematol. Oncol. Clin. North Am., 32 (2): 277-95, 2018.

8- SAGGAR K. and SOBTI P.: MRI Assessment of iron overload in thalassemia: An overview Rivista Italiana di Medicina dell'Adolescenza, 11 (1): 29-36, 2013.

9- FAHMY H.S., KHATER N.H., EL SHAHAT H.M., MADANI A.A., et al.: Reassessing the value of MRI T2* in evaluation of hepatic and myocardial iron concentration: An institutional study The Egyptian Journal of Radiology and Nuclear Medicine, 46: 1085-90, 2015.
10- WANG W., KNOVICH M.A., COFFMAN L.G., TORTI F.M., et al.: Serum ferritin: Past, present and future. Biochimica et biophysica acta, 1800 (8): 760-9, 2010.

11-ANDERSON L.J.: Assessment of Iron Overload with T2* Magnetic Resonance Imaging Prog. Cardiovasc. Dis., pp. 287-94, 2011.

12- PAKBAZ Z., FISCHER R., FUNG E., NIELSEN P., HARMATZ P., et al.: Serum ferritin underestimates liver iron concentration in transfusion independent thalassemia patients as compared to regularly transfused thalassemia and sickle cell patients. Pediatr. blood cancer, (49): 32932, 2007.

13- MUSALLAM K.M., CAPPELLINI M.D., WOOD J.C., GRAZIADEI G., et al.: Elevated liver iron concentration is a marker of increased morbidity in patients with $\beta$ thalassemia intermedia. Hematologica, (96): 1605-12, 2011.

14- CAPPELLINI M.D., COHEN A., PIGA A., BEJAOUI M., PERROTTA S., AGAOGLU L., et al.: A phase 3 study of deferasirox (ICL670), a once-daily oral iron chelator, in patients with beta-thalassemia. Blood, (107): 3455-62, 2006.

15- PAPAKONSTANTINOU O., ALEXOPOULOU E., ECONOMOPOULOS N., BENEKOS O., et al.: Assessment of iron distribution between liver, spleen, pancreas, bone marrow, and myocardium by means of $\mathrm{R} 2$ relaxometry MRI in patients with beta-thalassemia major. $\mathbf{J}$. Magnetic Resononance Imaging, 29: 853-9, 2009.

16-ANGELUCCI E., BRITTENHAM G.M., McLAREN C.E., RIPALTI M., BARONCIANI D., et al.: Hepatic iron concentration and total body iron stores in thalassemia major. N. Engl. J. Med., 343 (5): 327-31, 2000.

17- EL SHANSHORY M.R., AWAD M.A., EL SHAFEY R.A., SOLIMAN H.H., et al.: Evaluation of Liver Iron Concentrations in Children with Beta Thalassemia Infected with Hepatitis C Virus Before and After Spirulina Therapy by Magnetic Resonance Imaging. Arch. Blood Transfus. Disord., 1 (1): ABTD.000504, 2017.

18- MAJD Z., HAGHPANAH S., AJAMI G.H., et al.: Serum Ferritin Levels Correlation With Heart and Liver MRI and LIC in Patients With Transfusion-Dependent Thalassemia. Iran Red Crescent. Med. J., 17 (4): e24959, 2015.

19-NEUFELD E.J.: Oral chelators deferasirox and deferiprone for transfusional iron overload in thalassemia major: New data, new questions. Blood, May 1, 107 (9): 3436-41, 2006.

20- NIELSEN P., GUNTHER U., DURKEN M., et al.: Serum ferritin iron in iron overload and liver damage: Correlation to body iron stores and diagnostic relevance. J. Lab. Clin. Med., (135): 413-8, 2010.

21- OLIVIERI N.F. and BRITTENHAM G.M.: Final results of the randomized trial of deferiprone (L1) and deferoxamine (DFO). 


\section{تقويم تركيز الحديل في الكبد بالرنين المغناطيسى الدئ

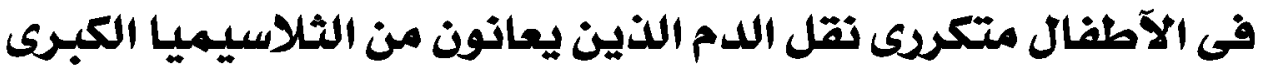

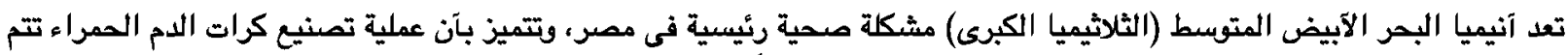

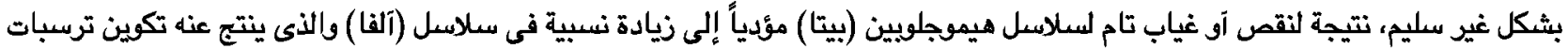

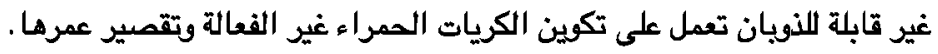

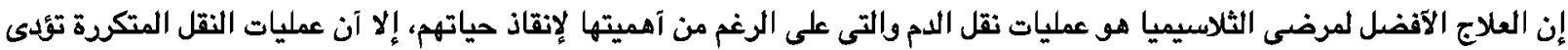

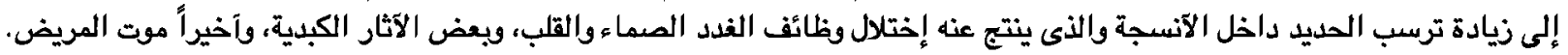
ويعد الكبد هو الموقع الرئيسى التخزين الزائد الحديد، وبالتالى، فإن تركيز الحديد فى الكبد يعكس بدقة إجمالى مخزن الحديد فى الجسم.

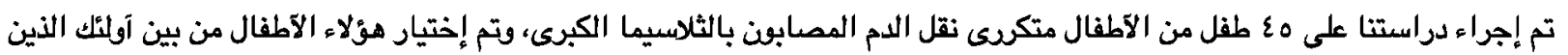

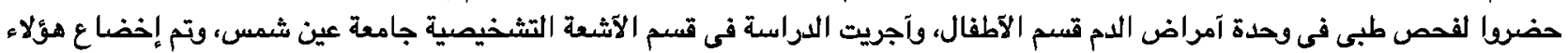
الآطفال لتحاليل معملية وللتصوير بالرئين المرافي المفاطيسى.

آظهرت نتائج اللراسة آنه مع تزايد نسبة الحديد فى الكبد تتناقص شدة الإثارة فى صور الرنين المفناطيسى المتمثلة فى T2* حيث آن

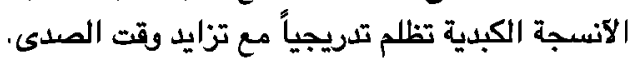

آظهرت دراستنا علاقة عكسية قوية بين نسبة الحديد فى الكبد وT2 وعلاقة طردية قوية بين نسبة الحديد فى الكبد وR2. كما آظهرت الدراسة عن وجود علاقة قوية بين مستوى (الفيريتين) ونسبة الحديد عندما يكون مستوى الفيريتين آقل من 4000ng/ml ولكن

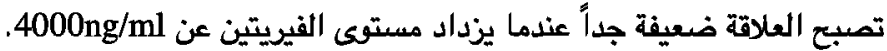

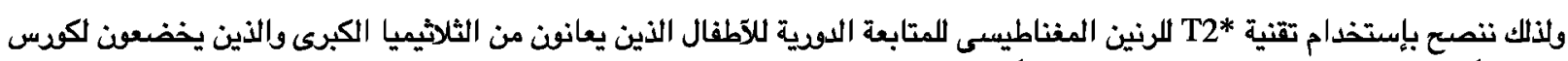

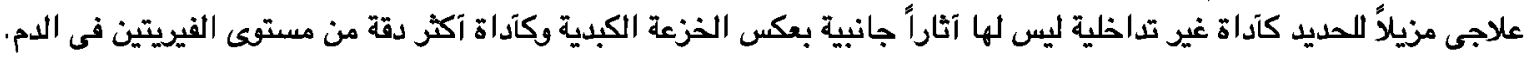

